\title{
RISK FACTORS AND DEVELOPMENTAL OUTCOME AMONG BABIES WITH PERINATAL ASPHYXIA IN A TERTIARY CARE CENTRE
}

\author{
Sudhakar Reddy', Natarajan Pachiappan², Bahubali Gane3, Revathy4 \\ ${ }^{1}$ Senior Resident, Department of Paediatrics, Sri Venkateshwara Medical College and Research Centre, Ariyur, Pondicherry. \\ ${ }_{2}^{2}$ Associate Professor, Department of Paediatrics, Sri Venkateshwara Medical College and Research Centre, Ariyur, Pondicherry. \\ ${ }^{3}$ Assistant Professor, Department of Paediatrics, Sri Venkateshwara Medical College and Research Centre, Ariyur, Pondicherry. \\ 4Junior Resident, Department of Paediatrics, Sri Venkateshwara Medical College and Research Centre, Ariyur, Pondicherry.
}

\section{ABSTRACT}

\section{BACKGROUND}

Birth asphyxia is commonest cause of preventable cerebral injury. It is also important cause of neonatal mortality. Incidence of birth asphyxia however is higher in developing countries and leading cause of neonatal mortality. This work is undertaken to study the incidence, risk factors and outcome of birth asphyxia.

\section{METHODOLOGY}

This study was conducted in the neonatal intensive care Unit of tertiary care hospital. Neonates with the APGAR score of less than 7 at 5 minutes were included in the study. Asphyxiated newborns who satisfied the inclusion criteria were enrolled in the study. A detailed prenatal, natal and postnatal history was obtained. A general physical examination was conducted which included temperature, heart rate, any apparent physical abnormality, weight, length and head circumference.

\section{OBSERVATIONS}

Total 684 cases admitted out of which 188 case were expired, 82 case left against medical advice, 414 (60\%) cases were improved. Out of 414 cases 156 lost to follow up. 258 cases followed up to one year of age. In the present study, a higher incidence of mortality was seen in babies delivered by instrumental deliveries 51.4\% (88 cases). Mortality in babies delivered by Emergency LSCS was $23.1 \%$ (52 Cases), while in normal vaginal delivery the incidence of mortality was $16.6 \%$ (48 cases).

\section{CONCLUSION}

The common predisposing factors of birth asphyxia were poor antenatal care (24\%) and meconium stained liquor (20\%). Both ante partum and intra partum factor are important in the causation of birth asphyxia. Improvement in public health of women with associated gains in female growth must remain a long term goal.

\section{KEYWORDS}

Perinatal Asphyxia, Risk Factors, Development.

HOW TO CITE THIS ARTICLE: Reddy S, Pachiappan N, Gane B, et al. Risk factors and developmental outcome among babies with perinatal asphyxia in a tertiary care centre. J. Evolution Med. Dent. Sci. 2016;5(19):947-949, DOI: 10.14260/jemds/2016/220

\section{INTRODUCTION}

Birth asphyxia is defined as the failure of a newborn to establish spontaneous respiration immediately following complete delivery. ${ }^{1}$ Birth asphyxia is the most common and important cause of preventable cerebral injury. ${ }^{2}$ Birth asphyxia is a important cause of neonatal mortality. Every year approximately 4 million babies are born asphyxiated. Incidence of birth asphyxia however is much higher in developing countries. It continues to be a major cause of neonatal mortality in developing countries.3,4 Maternal infections, prematurity and multiple births are important risk factors for birth asphyxia. ${ }^{5}$ So this work was undertaken to study the risk factors and outcome of birth asphyxia.

Financial or Other, Competing Interest: None.

Submission 21-01-2016, Peer Review 17-02-2016,

Acceptance 22-02-2016, Published 05-03-2016.

Corresponding Author:

Dr. Natarajan Pachiappan,

Associate Professor,

Department of Paediatrics,

Sri Venkateshwara Medical College and Research Centre,

Ariyur, Pondicherry.

E-mail: bahubaligane@gmail.com

DOI: $10.14260 /$ jemds $/ 2016 / 220$

\begin{abstract}
METHODOLOGY
This study was conducted in the neonatal intensive care Unit of tertiary care hospital, Puducherry. We included the neonates with the APGAR score of less than 7 at 5 minutes. Excluded the babies with major congenital malformation. Asphyxiated newborns satisfying the inclusion criteria were enrolled in the study, the findings were recorded on a standard Performa. A specially designed questionnaire was administered to assess the role of maternal and neonatal factors in asphyxia. A detailed history of the presenting complaints and the prenatal, natal and postnatal history was obtained. Mode of delivery was noted. A general physical examination was conducted which included temperature, heart rate, any apparent physical At each visit, detailed neurological examination was done and development assessment was done using Trivandrum Development Screening Test. weight, length and head circumference were noted. Babies were followed up to one year of age.
\end{abstract}

\section{OBSERVATIONS}

There were 11075 babies delivered during the march 2010 to march 2011, out of which 684 had perinatal asphyxia. 
All babies with perinatal asphyxia were examined and the data recorded. Distribution of babies according to gender is given in Fig. 1.

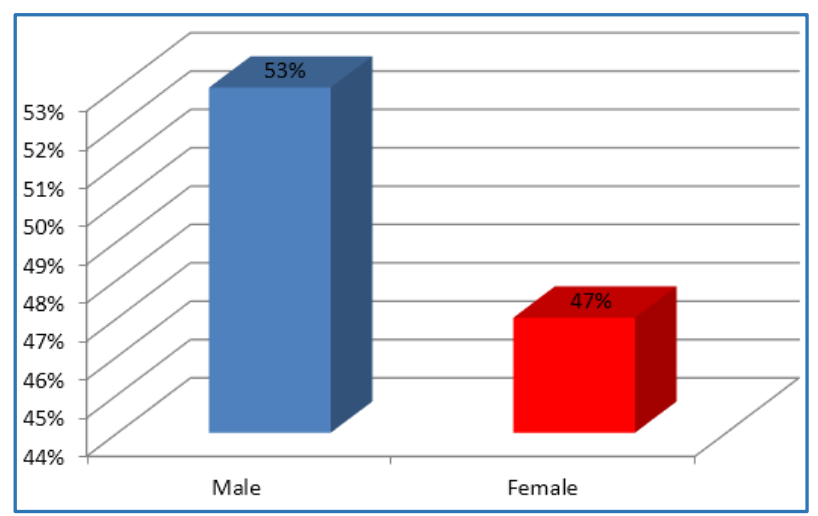

Fig. 1: Distribution of Cases According to Gender

Newborns with birth weight 2500-4000gm accounted for $81.2 \%$ of infants, while less than 2500 gm were $15.7 \%$ and those more the $4000 \mathrm{gm}$ were $2.9 \%$ (Table 1). Distribution according to maternal age is given in Fig. 2.

\begin{tabular}{|c|c|c|}
\hline Birth Weight & No. of Cases & Percentage \\
\hline $1000-1499$ & 49 & $7 \%$ \\
\hline $1500-2499$ & 59 & $8.6 \%$ \\
\hline $2500-2999$ & 262 & 38.3 \\
\hline $3000-3499$ & 218 & 31.8 \\
\hline $3500-3999$ & 76 & 11 \\
\hline \multicolumn{2}{|c|}{ Table 1: Distribution of Cases According to Birth Weight } \\
\hline
\end{tabular}

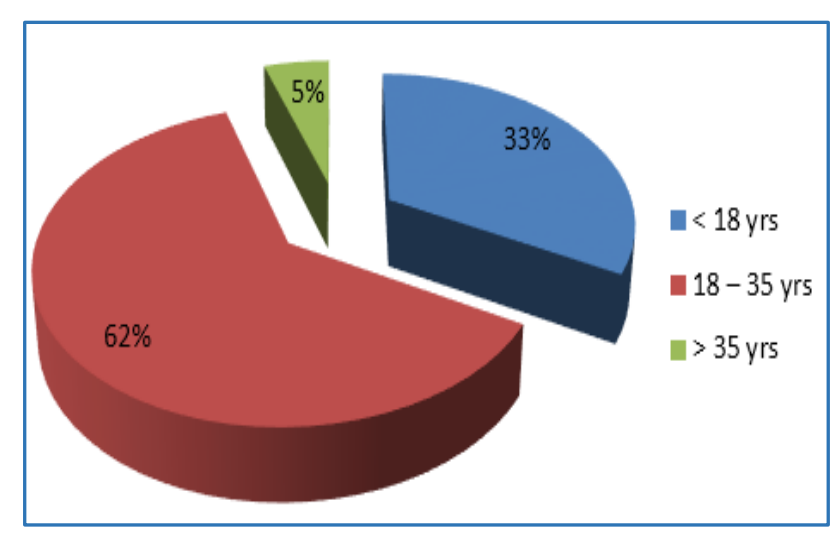

Fig. 2: Distribution according to maternal age

\begin{tabular}{|c|c|c|}
\hline Predisposing Factors & $\begin{array}{c}\text { No. of } \\
\text { Cases }\end{array}$ & Percentage \\
\hline ANC visit less than 3 & 59 & 23.9 \\
\hline $\begin{array}{c}\text { Ante partum } \\
\text { hemorrhage }\end{array}$ & 5 & 2.03 \\
\hline $\begin{array}{c}\text { Pregnancy induced } \\
\text { hypertension }\end{array}$ & 28 & 11.3 \\
\hline Age < 18 yrs & 30 & 12.1 \\
\hline Age > 35 yrs & 6 & 2.4 \\
\hline $\begin{array}{c}\text { Maternal fever at the } \\
\text { time of delivery }\end{array}$ & 4 & 1.6 \\
\hline $\begin{array}{c}\text { Premature rupture of } \\
\text { membrane }\end{array}$ & 14 & 5.6 \\
\hline $\begin{array}{c}\text { Prolonged 2nd stage } \\
\text { labour }\end{array}$ & 32 & 13.1 \\
\hline
\end{tabular}

\begin{tabular}{|c|c|c|}
\hline Malpresentation & 9 & 36 \\
\hline $\begin{array}{c}\text { Meconium stained } \\
\text { liquor }\end{array}$ & 49 & 19.9 \\
\hline Prematurity & 7 & 2.8 \\
\hline Multiple Births & 3 & 1.2 \\
\hline Table 2: Predisposing Factors of Birth Asphyxia \\
\hline
\end{tabular}

The common predisposing factors of birth asphyxia were poor antenatal care $(24 \%)$, meconium stained liquor $(20 \%)$, prolonged labour (13\%), maternal age <18yrs (12\%), PIH (11\%). More than one risk factor were present in $54 \%$ of cases (Table 2)

\begin{tabular}{|c|c|c|}
\hline Organ System & No. of Cases & Percentage \\
\hline Renal & 287 & 42 \\
\hline Respiratory & 259 & 38 \\
\hline CVS & 198 & 29 \\
\hline GIT & 109 & 16 \\
\hline Hematological & 82 & 12 \\
\hline \multicolumn{2}{|c|}{ Table 3: Distribution of Organ System Involvement } \\
\hline
\end{tabular}

Commonest organ involved was renal. $42 \%$ of the babies had renal involvement. Other organs involved were pulmonary $38 \%$, CVS 29\%, GIT 16\% Haematological 12\% (Table 3).

Total 684 cases admitted out of which 188 case were expired, 82 case left against medical advice, 414 (60\%) cases were improved. Out of 414 cases 156 lost to follow up. 258 cases followed up to till one year of age. In the present study, a higher incidence of mortality was seen in babies delivered by abnormal vaginal labour $51.4 \%$ (88 cases). Mortality in babies delivered by Emergency LSCS was $23.1 \%$ (52 Cases), while in normal vaginal delivery the incidence of mortality was $16.6 \%$ (48 cases).

\begin{tabular}{|c|c|}
\hline Motor development delay & 40 \\
\hline Mental Development Delay & 32 \\
\hline Seizures & 18 \\
\hline Hearing \& Speech problems & 12 \\
\hline Ocular problems & 28 \\
\hline Microcephaly & 8 \\
\hline Hydrocephalus & 2 \\
\hline Recurrent infection & 19 \\
\hline Aspiration Pneumonia & 20 \\
\hline Feeding Difficulties & 32 \\
\hline \multicolumn{2}{|c|}{ Table 4: Outcome at one year of Age } \\
\hline
\end{tabular}

Total 258 cases were followed up to age of one year, 72 cases had abnormal development 40 cases had abnormal motor development while 32 cases were delay in mental development. Associated problems like seizures in 18 cases, ocular problems like refractory errors, Strabismus in 28 cases, defect in hearing and speech in 12 cases, slow head growth in 8 cases, hydrocephalus in 2 cases, feeding difficulties in 32 cases. Recurrent infections and aspiration pneumonias were noticed in 19 and 20 cases respectively (Table 4).

In present study a higher incidence of mortality was seen in birth weight between $1.5-2.5 \mathrm{~kg}$ babies (42\%). The incidence of morality babies weighing between 2.5 - $4 \mathrm{Kg}$ was $21 \%$, while in babies weighing more than $4 \mathrm{~kg}$ had mortality of $15 \%$.

\section{DISCUSSION}

According to WHO Birth Asphyxia is leading cause of neonatal mortality in developing Countries. Perinatal asphyxia accounts for 20 percent of infant mortality rate. 
In present study, the magnitude of problems of birth asphyxia was considerably high. The incidence of birth asphyxia was $6.1 \% 684$ had birth asphyxia in 11, 075 deliveries. Similar results were noted in some of the prior studies.6-8 Studies from developed Countries showed lower incidence. ${ }^{9-13}$ The high incidence of birth asphyxia in present study was attributed to the fact that Govt.

Being a tertiary care hospital, most of referral are from nearby primary centers and remote places, which may lead to delay in reaching hospital, which is one of the cause for higher incidence of asphyxia in this study. Out of 684 babies, 188 died due to severe CNS involvement and multi-organ failure. 124 babies had abnormal neurological examination at the term discharge. Of the 72 Cases with abnormal development, 40 cases had motor delay in motor development 32 are delayed in social language developments. Seizures in 18 cases, ocular problems like squint, refractory errors in 28 cases. Abnormal outcome was observed in majority of babies who had no antenatal check-ups. Abnormal outcome was observed in majority of babies who had no antenatal check-ups. Unfavourable outcome noticed in majority of infants delivered at preterm gestation, which was statistically significant.

Breech presentation, forceps delivery and induced labour were apparently associated with higher incidence of developmental delay, the difference is statistically significant. The development delay was observed more in babies belonging to low socio economic status compared to middle and high economic status, which is statistically significant

\section{CONCLUSION}

The common predisposing factors of birth asphyxia were poor antenatal care (24\%), meconium stained liquor (20\%), prolonged labour (13\%), maternal age <18yrs $(12 \%)$, PIH (11\%). More than one risk factor was present in 54\% of cases. Higher incidence of mortality was observed in low birth weight babies (42\%) and preterm babies (41\%). Both ante partum and intra partum factor are important in the causation of birth asphyxia. Improvement in public health of women with associated gains in female growth must remain a long term goal.

\section{REFERENCES}

1. NNPD. www,newbornwhocc.org/pdf/nnpd_report 2002-03.PDF. 2003. Accessed 20th March 2013.

2. Bryce J, Boschi C, Shibuya K, et al. WHO estimates of the causes of death in children. Lancet 2005;365(9465):1147-52.

3. Lawn JE, Cousens S, Zupan J. 4 million neonatal deaths: when? where? why? Lancet 2005;365(9462):891-900.

4. Lawn J, Shibuya K, Stein C. No cry at birth: global estimates of intrapartum stillbirths and intrapartumrelated neonatal deaths. Bull World Health Organ 2005;83(6):409-17.

5. World health organization. The world health report shaping the future. Geneva World Health Organization 2003;p-68-73.

6. Costello AM, Manandhar DS. Perinatal asphyxia in less developed countries. Arch Dis Child 1992;71(9):FI-F3.

7. Bhargava SK, Batra A, Sen Gupta A, et al. Study of asphyxia neonatorum. J ObstetGynecol India 1988;38:162-166.

8. Chandra S, Ramji S, Thirupuram S. Perinatal asphyxia: multivariate analysis of risk factors in hospital births. Indian Pediatr 1997;34(3):206-212.

9. Ferriero DM. Neonatal brain injury. N Engl J Med 2004;351:1985-95.

10. The world health report 1995. Geneva: World Health Organization; 1997;p-21.

11. Fatemi A, Wilson M, Johnston M. Hypoxic-ischemic encephalopathy in the term infant. Clin Perinatol 2009;36(4):835-858.

12. Shalak L, Perlman J. Hypoxic-ischemic brain injury in the term infant-current concepts. Early Hum Dev 2004;80(2):125-141.

13. Johnston MV, Ishida A, Ishida WN. Plasticity and injury in the developing brain. Brain Dev 2009;31(1):1-10. 